\title{
Multi Criteria Decision-Making Method: An Overview of Application in Project Appraisal
}

\author{
Author: Mostafa KERAMAIKERMAN \\ Affiliation: University of Liverpool, UK - Member, Institute of Electrical and Electronics Engineers
}

(IEEE)

E-mail:mkkeramati@gmail.com, Mostafa.Keramati@ieee.org

DOI $<10.26821 /$ IJSRC.8.3.2020.8303>

\begin{abstract}
The author has undertaken a literature review to examine the MCDM applicability in different contextual settings as well as the methods that are used as part of the decision-making process associated with infrastructure projects.
\end{abstract}

Keywords: Multi-criteria decision making, MCDM, Analytic Hierarchy Process, AHP, Project appraisal.

\section{INTRODUCTION}

The MCDM application is wide, diverse and can almost fit for any circumstances when the intention is to make a selection among a number of options. Regardless of the business type and industry, every organization should determine its target market/sector to effectively allocate the required resources toward realizing the organizational growth strategy. This can only be realized if the forthcoming projects are appraised unbiasedly and through a collective decisionmaking process.

The organizations often tend to appraise the projects from their particular business standpoint of which this could result in neglecting other project selection variables. It is, therefore, crucial to view the appraisalprocess from various perspectives to obtain a broader picture of the project and its long term impacts. However, given the conflicting nature of project selection criteria; it is almost impractical to independently appraise a project without considering a multi criteria-based decision support approach.For example, Schaaf et al., (2008) investigate the project selection process for the US military in various countries by considering a confined number of metrics that only address the concerns of the project executing organization. The appraisal here isprimarily limitedto the project selection as well as implementation criteria, and less attention is given to the long-term objectives.This one-sided approach has marginalized viewing the appraisal from the full project life cycle as well asthe cross-stakeholder perspective. The criteria for project selection are often focused on, e.g., material availability, hazard, transport cost, and local support, which mainly represent the project execution challenges and dismisses the importance of other factors toward a multi-criteria decision making.

This biased approach has further influenced the way stakeholders are viewed in the appraisal process. In particular, the criteria used for project selection, primarily address the US government's interest over the appraised 
projects while the interest of other stakeholders such as the host country and the local community is largely marginalized. The criteria here mainly address the US government concerns related to the prospective projects which pose a high degree of uncertainty in terms of required commitments from other stakeholders in terms ofproject implementation, as well as the subsequent operation.

The study conducted by Gurgur and Morley (2008) also represent a similar appraisal approach with Schaaf et al., (2008) where the project selection for Lockheed Martin Space system company is not viewed from the full project lifecycle, and only project selection and operation phases are taken into account. This two-dimensional approach is further extended to project selection criteria in which the identified criteria are largely related to the cost, $\mathrm{NPV}^{1}$, profitability, etc. It is worth to note that, limiting the selection criteria to a small number of tangible metrics confine the credibility of the appraisal process as other intangible metrics are largely sidelines and not considered during the decision-making process, and therefore the subsequent findings will not be valid and vigorous enough.

Given the above constraints associated with project appraisal, the organizations should find common ground where all the conflicting interests of the stakeholders are integrated toward an unbiased appraisal mechanism. The MCDM facilitates such cross-stakeholder consultation frameworks where the views are collected independently and utilized toward an evidence-based decision-making approach. Furthermore, the information scarcity is a common challenge that many organizations face at the time of project appraisal of which MCDM is well placed to utilize the existing information toward a systematic decision-making mechanism (Marcelo Gordillo, Mandri-Perrott, House, \& Schwartz, 2016).

\section{MCDM Application}

\subsection{Site selection for infrastructure projects}

Site selection for infrastructure projects is a common practice for every project undertaking and it is done as part of project pre-feasibility study and during the appraisal stage. It is crucial to identify the potential project sites as early as possible as the location of the project has a great economic, environmental and social influences over project life cycle from appraisal stage up to operation and maintenance phases. Selecting the most optimized route/location for power transmission lines, crude oil/gas pipelines, roads, power plants, etc. is highly important as any incorrect selections may cause irreversible impacts that fundamentally challenge the overall project viability. It is, therefore, with utmost importance to consider a varied range of criteria when selecting project site for any kind of infrastructure projects.

Sepehr et al., (2017) utilizes a combination of Delphi method and spatial analysis to evaluate a number of potential sites for construction of a desalination plant in the south of Iran. This mixed-method is used to identify the potential site locations by taking into account the experts' views in rating different selection criteria for the potential sites. The findings demonstrate a qualitative comparison among different potential sites and suggest a shortlisting of the most feasible sites for implementation, but no project ranking/prioritization is provided to guide further project appraisal. The Delphi method here provides a list of potential sites, but no suggestion is given in terms of preferences and eventually not assistive enough as a decision support system. Furthermore, the criteria used 
Volume 8 Issue 3 March 2020

for site selection mainly represent the environmental and social aspects of the project and less emphasisis given to financial/economic criteria. This is because the Delphi method is incapable of analyzing financial variables and therefore, this one-sided method approach poses less degree of confidence to the final outcomes. What is worth mentioning here is that; the right choice of project appraisal method is tightly correlated with the type of problem to be solved (Nedevska, Krakutovski, \& Zafirovski, 2017). It is, therefore vital to first decompose the problem and comprehend the desired objectives which help in selecting the most appropriate decision support system method.

In contrast, the MCDM application for site selection can ease the process and bring more clarities in terms of preferred site locations. For instance, Popvic et al., (2017) employ Compromise Programming as the preferred MCDM method to prioritize some resort project sites in Serbia. The outcomes indicate that MCDM can facilitate a decision-making platform where a number of criteria are compared against one another which eventually fosters more supportive findings in project site selection. Nedevska et al., (2017) also utilize a mixed and comparative MCDM method to determine the best alternative route for a railroad project. The combination of three different MCDM methods of; Weighted Sum Model (WSM), AHP and VIKOR facilitate developing a robust decision support system in where the findings from every method are compared against one another to conclude the best feasible project alternatives.

It is obvious that the traditional and qualitative decision-making method is only able to consider one criterion, while the MCDM method is a multidimensional approach, allowing decisionmakers to deal with a number of conflicting criteria. This clearly highlights the ineffectiveness of the traditional method for infrastructure project site selection as compromising other criteria with only a single criterion can result in a wrong decision and unexpected outcome.

\subsection{MCDM application in various business contexts}

MCDM can be used as a tool for organizations to decide on the best practical market entry approach. Mohanty(1992), indicates how the MCDM method is used to formulate the overall market penetration strategy for an Indian construction company that is willing to enter into an international business venture. The company in question is a privately-owned construction firm, and therefore, the criteria used for project selection and subsequent market penetration approach are often centered on business profitability as well as implementation feasibility. It is worth noting that; the variations between decision-making processes are the result of differences between organizational structure, strategic mission and leadership approach (Christian, Hui, \& Kongkiti, 2014, p. 569) of which this clearly reflects the project selection process within the Indian construction company. In such organizationalcontexts, the financial return is regarded as a pivotal point for every business proposal, and further consideration can be justified if the proposed business perceived financially viable. However, the social, environmental, organizational objectives as well as long terms impacts of the projects should also be taken into account during project appraisal of which these criteria are not often regarded crucial when the profitability is the prime intention.

\subsection{MCDM facilitates cross-stakeholders consultation mechanism}


Volume 8 Issue 3 March 2020

The project appraisal process for infrastructure projects is a cross-stakeholders exercise, and there is often a different group of beneficiaries where each has its own objective and interest. It is almost impractical to integrate all stakeholders' inputs during project appraisal by using traditional decision-making method. Mishra et al., (2013) demonstrate the challenges encountered toward appraising the public transport project where the interest of the three different entities (public investors, private investors, and commuters) have to be taken into account. The MCDM is well responsive in addressing such complex settings and can help the decision-makers to gather a diverse range of views from the stakeholders, and have them integrated toward an MCDM-based method. Mishra et al., (2013) employ AHP to narrow down a number of options for the decisionmakers while the Multi-objective optimization method is deployed toward facilitating an MCDM-based approach. The findings here proves the usefulness of the MCDM method for a cross-stakeholders engagement approach which underscores the applicability of MCDM method for such a consultative approach.

\subsection{MCDM facilitates, conflict resolution among stakeholders and smoothen the project appraisal process}

The appraisal process for infrastructure projects is often considered a contradictory practice due to the presence of a different group of stakeholders as well as their conflicting interests. Furthermore, every group of stakeholder has a different perception about other party's interest and expectations of which this understanding might not necessarily be correct. Such conflicting environment makes the process much more complicated and uncertain for the project implementing organizations and often is considered as the root cause of conflict of interest among the stakeholders (Olander \&
Landin, 2008). It is, therefore, vital to understand the stakeholder's expectations at project appraisal stage which can facilitate smooth implementation. Interestingly, the MCDM method is regarded as a structured approach in dealing with such complex decisionmaking settings. It allows the implementing organizations to decompose the problem and objectively examine the interests of the various stakeholders and have them all incorporated toward a consultative decision-making approach.

In contrast, the traditional qualitative decisionmaking mechanism is incapable of addressing the conflicts among stakeholders during project appraisal stage. However, despite the inadequacy of this qualitative method, the approach is still widely practiced among project/portfolio professionals whopose various implementation risks. For example, Ionescu, Burduja, andBurlacu(2016) have shown no interest in MCDM application in appraising a road project in Romania as the selection process is solely undertakenqualitatively. Although, such a qualitative method, poses fewer complications to the decision-making process but the outcomes are not valid and robust enough to be considered as a decision support system. This method is commonly used in the top-down approach where the objectives are already identified and determined by the key decision-makers and interests of other stakeholders are not considered valuable.

\subsection{Integration of MCDM with traditional cost-benefit project appraisal method}

The financial metrics are widely used for project appraisal and often considered an important criterion to gauge project viability. In particular, the financial indicators such as; Net Present Value (NPV), Return of Investment (RoI), Rate of Return (RoR), etc. are traditionally and still commonly used as the major factors in project 
Volume 8 Issue 3 March 2020

appraisal and often considered as the prime indicator for investment decision making. However, these quantifiable criteria, cannot entirely support a genuine multi-criteria decision-making support system as in many circumstances other intangible criteria should also be taken into account. The academic scholars underline how the NPV and other costeffectiveness criteria are dominating other nontangible project appraisal criteria for the investment decision making related to the public infrastructure projects such as public health care facilities (Christian et al., 2014). This poses a substantial concern over the effectiveness and usefulness of such publicly targeted facility as evidently the comfort and preferences of the end user should always come first during project appraisal rather than the cost-effectiveness metric.

In fact, the nonmonetary criteria are often intangible, and their profitability/impact contribution is indirect, and therefore, the project e.g., RoR, NPV, RoI and other fiscal criteria should not solely be taken into account for project selection.(Gurgur \& Morley, 2008, p. 253). Being said that, other nontangibleprojectattributes such as; social, strategic objectives, resilience, etc. should also be considered in the process of project selection.

This one-sided cost-benefit decision-making approach is no longer responsive to today's sustainability needs and can only represent the economic dimension of the sustainability triangle. To that end, such a monodimensional approach should either be used in combination with other MCDM methods or as a supportive tool toward validating the findings being developed through other decision-making techniques. To that end, the integration of tangible project appraisal criteria such as; NPV, RoI, etc. with other intangible metrics can substantiate the project appraisal process and develop a robust decision support system.

\subsection{AHP, a preferred project appraisal/prioritization within the MCDM context}

An extensive literature review of over 150 academic papers related to AHP application in different study areas indicates the broad applicability of the AHP method (Vaidya \& Kumar, 2006) and in particular its suitability as a preferred tool within MCDM context. The study has shown that AHP is used for ten different research topic categories including; selection, evaluation, benefit-cost analysis, resource allocation, planning and development, priority and ranking, decision making, forecasting, medicine, and quality function deployment. The study further suggests the popularity of AHP method in personal, social, manufacturing, political, engineering, education, industry, and government application areas.

Interestingly, AHP is quite flexible to be integrated with other analytical methods which enable the user to generate a robust outcome which is derived from a combined method and brings more creditability to the whole process. AHP is widely used in combination with other techniques toward developing a hybrid method which has made AHP a preferred analytical option. In particular, AHP is quite compatible with other decision-making techniques such as; fuzzy logic (Nguyen, Fong, \& Ho, 2007), Delphi (Sepehr et al., 2017), etc. which allows a hybrid/evidence-based decision-making approach for almost any complex situations. It is worth noting that, the combination of AHP with other decision-making methods is complementary where the integration of either of these techniques with AHP can reinforce the final findings and results in more accurate outcomes. For instance, Delphi method can 
Volume 8 Issue 3 March 2020

bring more validity to the data collection, survey, stakeholder engagement and pairwise comparison that should be undertaken as part of the AHP method and prior to data analysis. A valid data collection technique and input from the stakeholders can pose a higher degree of confidence to the decision-makers when the AHP findings are out. The ultimate intention in utilizing AHP is to develop a decision support system, and the degree of the achievement is tightly correlated with the quality of the input fed into the process. The applicability of AHP for project prioritization and within a multi-criteria decision making context is clearly demonstrated by Vargas (2010). The mixed model research is employed for primary/secondary data collection, and the qualitative data are then quantified and utilized for numerical data analysis. Thisclearlyoutlines the suitability of AHP method for project selection/prioritization where a number of conflicting criteria are integrated toward an MCDM based approach.

\subsection{Conclusion}

The necessity of collecting all contrasting view at the time of project appraisal is becoming an important factor for many enterprises and particularly within the Research and Development sector. This is because the corporates can not afford to spend thousands of man/hours and precious resources for the desired project where the implementation and targeted objectives are compromised with unforeseen barriers which could potentially challenge the project viability. To that end, it is crucial to collect all the views toward developing a multicriteria decision-making mechanism which allows the proposed project to be gauged against all variables and independent of any biased standpoint.

\section{References}

Christian, W., Hui, Z., \& Kongkiti, P. (2014). International study of technology investment decisions at hospitals. Industrial Management \& Data Systems, (4), 568. doi:10.1108/IMDS-102013-0422

Gurgur, C. Z., \& Morley, C. T. (2008). Lockheed martin space systems company optimizes infrastructure project-portfolio selection. Interfaces, (4), 251. doi:10.1287/inte.1080.0378

Ionescu, H. M., Burduja, S. I., \& Burlacu, F. A. (2016). Improved prioritization criteria for road infrastructure projects. Romanian Journal of Transport Infrastructure, Vol 5, Issue 2, Pp 1027, (2), 10. doi:10.1515/rjti-2016-0045

Marcelo Gordillo, D., Mandri-Perrott, X. C., House, R. S., \& Schwartz, J. (2016). Prioritizing infrastructure investment : A framework for government decision making. (Policy Research working paper No. WPS 7674). Washington, D.C.: World Bank Group.

Mishra, S., Khasnabis, S., \& Swain, S. (2013). Multi-entity perspective transportation infrastructure investment decision making doi:https://doiorg.liverpool.idm.oclc.org/10.1016/j.tranpol.201 $\underline{3.07 .004}$

Mohanty, R. (1992). Project selection by a multiple-criteria decision-making method: An example from a developing country. International Journal of Project Management, 10(1), 31-38. doi:10.1016/0263-7863(92)90070$\mathrm{P}$

Nedevska, I. Z., Krakutovski, Z. M., \& Zafirovski, Z. S. (2017). Application of different methods of multicriteria analysis for railway route selection. Tehnika, Vol 72, Iss 6, Pp 797$805 \quad$ (2017), (6), 797. doi:10.5937/tehnika1706797N

Nguyen, H. L., Fong, C., \& Ho, C. (2007). Using analytical hierarchy process in decision analysis - the case of vietnam state securities commission., 139-1144. doi:10.1109/IEEM.2007.4419168 
Olander, S., \& Landin, A. (2008). A comparative study of factors affecting the external stakeholder management process. Construction Management and Economics, 26(6), $553-561$

doi:10.1080/01446190701821810

Popovic, G., Dragiša Stanujkic, \& Vesna Pašic Tomic. (2017). Resort project selection by using compromise programming. Progress in Economic Sciences, Iss 4 (2017), (4) doi:10.14595/PES/04/017

Schaaf, R. E. V., DeLaurentis, D. A., \& Abraham, D. M. (2008). Multi-objective optimization models for improved decisionsupport in humanitarian infrastructure project selection problems. United States: THE INSTITUTE OF ELECTRICAL AND ELECTRONICS AND ELECTRONICS ENGINEERS.

Sepehr, M., S.M.R. Fatemi, Danehkar, A., \& Mashinchian Moradi, A. (2017). Application of delphi method in site selection of desalination plants. Global Journal of Environmental Science and Management, Vol 3, Iss 1, Pp 89-102 (2017),

(1), doi:10.22034/gjesm.2017.03.01.009

Vaidya, O. S., \& Kumar, S. (2006). Analytic hierarchy process: An overview of applications doi:https://doi-

org.liverpool.idm.oclc.org/10.1016/j.ejor.2004.0 $\underline{4.028}$

Vargas, R. V. (2010). Using the analytic hierarchy process (ahp) to select and prioritize projects in a portfolio. Paper presented at the Conference 